\title{
The quest for the identification of pathogenic patent foramen ovale
}

\author{
La búsqueda de la identificación del foramen oval permeable patogénico \\ Sebastián Francisco AMERISO ${ }^{1,2}$
}

${ }^{1}$ Fleni, Departamento de Neurología, Buenos Aires, Argentina.

${ }^{2}$ Fleni, Centro Integral de Neurología Vascular, Buenos Aires, Argentina.

SFA (D) https://orcid.org/0000-00018933-0847

Correspondence: Sebastián Francisco Ameriso; Email: sameriso@fleni.org.ar. Conflict of interest: There is no conflict of interest to declare. Received on August 08, 2021; Accepted on August 09, 2021.

\section{(cc) BY}

$\mathrm{P}$ atent foramen ovale (PFO) causing right-to-left shunt (RLS) has been demonstrated to be an important condition present in patients with ischemic strokes without other underlying predisposing factors. It constitutes $95 \%$ of RLS, being the rest pulmonary arteriovenous fistulae and other defects of the auricular septum ${ }^{1}$. In healthy subjects, PFO is found in $24.2 \%$ of autopsies, $23.7 \%$ of contrast-enhanced transesophageal echocardiogram (cTEE), $31.3 \%$ of contrast-enhanced transcranial Doppler (cTCD), and $14.7 \%$ of contrastenhanced transthoracic echocardiogram $(\mathrm{cTTE})^{1}$. These percentages are higher in cryptogenic strokes, especially in young subjects ${ }^{1,2}$.

Numerous reports have established an important role of size and other anatomical characteristics of the PFO that may increase the likelihood of causing strokes ${ }^{3}$.

PFO-associated stroke is today a well-recognized entity with specific diagnostic and therapeutic approaches ${ }^{4,5,6,7,8}$.

However, the high prevalence of PFO in the general population highlights the need to better define the characteristics of the malformation that exacerbates the risk and makes the causal association more likely.

In the current issue of Arquivos de Neuro-Psiquiatria, Scavasine VC et al. performed an elegant study of stroke patients with RLS using cTCD with Valsalva maneuver ${ }^{9}$. They correctly assumed that most of these shunts are caused by $\mathrm{PFO}^{1}$. The population was divided into two groups: undetermined embolic strokes and non-cardioembolic strokes. This strategy was used to assess the characteristics of PFOs in cases with a clear potential association with stroke and to compare them with PFOs unlikely to be related to the stroke. The authors found that more subjects in the embolic group had more than 10 microembolic signals, and $78 \%$ of them had RLS at rest compared with $58 \%$ in the noncardioembolic group. Both these findings indirectly suggest the presence of a larger PFO size in patients with embolic strokes compared with those in whom PFO was a "casual bystander" phenomenon.

These findings add to the current body of evidence indicating a potential association between the PFO size and the risk of paradoxical embolic stroke ${ }^{3}$.

Currently, there is a consensus in the management of PFO-associated strokes in young subjects with recent stroke and no other predisposing factors ${ }^{7,8}$. However, a large number of suspicious cases do not fit these criteria. Older subjects, those with transient ischemic attacks, coexistence of vascular risk factors, and/or other potential causes of stroke constitute a large proportion of patients without clear evidences to decide a proper approach ${ }^{8}$.

The study by Sacavasine et al. ${ }^{9}$ may help, using a simple and noninvasive methodology, to start filling this important gap in our knowledge.

\section{References}

1. Koutroulou I, Tsivgoulis G, Tsalikakis D,

Karacostas D, Grigoriadis N, Karapanayiotides T.

Epidemiology of patent foramen ovale in general population and in stroke patients: a narrative review. Front Neurol. 2020 Apr;11:281. https://doi. org/10.3389/fneur.2020.00281 
2. Bang OY, Lee MJ, Ryoo S, Kim SJ, Kim JW. Patent foramen ovale and stroke-current status. J Stroke. 2015 Sep;17(3):229-37. https://doi. org/10.5853/jos.2015.17.3.229

3. Patel K, Doshi R, Goyal H, Shah P, Meraj P. Transcatheter patent foramen ovale closure versus standard medical therapy for prevention of recurrent stroke: Updated Meta-analysis with an importance on shunt size. Eur J Intern Med. 2018 Nov;57:e31-e33. https://doi.org/10.1016/j.ejim.2018.08.009.

4. Mas J-L, Derumeaux G, Guillon B, et al. Patent foramen ovale closure or anticoagulation vs. antiplatelets after stroke. N Engl J Med. 2017 Sep;377(11):1011-21. https://doi.org/10.1056/NEJMoa1705915

5. Saver JL, Carroll JD, Thaler DE, et al. Long-term outcomes of patent foramen ovale closure or medical therapy after stroke. N Engl J Med. 2017 Sep;377(11):1022-32. https://doi.org/10.1056/ NEJMoa1610057

6. Søndergaard L, Kasner SE, Rhodes JF, Andersen G, Iversen HK, Nielsen-Kudsk JE, et al. Patent foramen ovale closure or antiplatelet therapy for cryptogenic stroke. N Engl J Med. 2017;377:1033-42. https://doi.org/10.1056/NEJMoa1707404

7. Elgendy AY, Saver JL, Amin Z, Boudoulas KD, Carroll JD, Elgendy IY, et al. Proposal for updated nomenclature and classification of potential causative mechanism in patent foramen ovale-associated stroke.JAMA Neurol. 2020 Jul;77(7):878-86. https://doi.org/10.1001/ jamaneurol.2020.0458

8. Kernan WN, Ovbiagele B, Black HR, Bravata DM, Chimowitz MI, Ezekowitz MD, et al. Guidelines for the prevention of stroke in patients with stroke and transient ischemic attack: a guideline for healthcare professionals from the American Heart Association/ American Stroke Association. Stroke. 2014 Jul;45(7):2160-236. https://doi.org/10.1161/STR.0000000000000024

9. Scavasine VC, Chamma JS, Bazan R, et al. Comparison of right-to-left shunt in cryptogenic embolic ischemic stroke and non-cardioembolic ischemic stroke. Arq Neuro-Psiquiatr 2021;79(10): 859-63. https:// doi.org/https://doi.org/10.1590/0004-282X-ANP-2020-0430 